\title{
A review of bioresorbable scaffolds: hype or hope?
}

\author{
Huay Cheem ${\underline{\operatorname{Tan}^{1}}}^{\text {, MBBS, FACC, Rajiv Ananthakrishna }}{ }^{1}$, MD, DM
}

In the field of percutaneous coronary intervention, the evolution of coronary metal stents has been well established for the past three decades, but research on bioresorbable scaffolds has only gained momentum in the recent past. Although second-generation drug-eluting metal stents are the gold standard for the treatment of obstructive coronary artery disease, a few drawbacks exist. The development of bioresorbable scaffolds is an attempt to overcome the limitations of metal stents. This review highlights the rationale for the bioresorbable scaffold, its properties and potential applications. It also focuses on the current evidence and concerns regarding the application of the bioresorbable scaffold in day-to-day practice.

Keywords: bioresorbable scaffold, coronary artery disease

\section{INTRODUCTION}

Bioresorbable scaffolds (BRSs) are considered a major advance in the field of percutaneous coronary intervention. ${ }^{(1)}$ They are designed to overcome the drawbacks of metallic drug-eluting stents (DESs), which include chronic local inflammatory reaction, absence of physiological coronary vasomotion, late stent thrombosis and the prevention of future coronary artery bypass surgery at the same site. ${ }^{(2-5)}$ The Absorb Bioresorbable Vascular Scaffold (BVS; Abbott Vascular, Santa Clara, CA, USA), one of the most extensively evaluated BRSs, has been subjected to numerous studies. This review will critically analyse the potential safety, efficacy and complications of BRSs.

\section{POTENTIAL BENEFITS OF BIORESORBABLE SCAFFOLDS}

The BRS system works in three phases to achieve vascular reparative therapy: revascularisation, restoration and resorption. In the revascularisation phase, the BRS is intended to mimic the characteristics of the metallic DES (i.e. scaffold deployment with minimum recoil, provision of high radial strength and controlled release of an antiproliferative drug). Subsequently, in the restoration phase, vasomotion of the vessel is re-established, and there is a transition from active to more passive support. The resorption phase is characterised by the degradation and metabolism of the scaffold. ${ }^{(6)}$

The BRS offers unique advantages that are not found in a metallic DES: (a) The restoration of coronary vasomotion is one of the main benefits. The BRS allows recovery of the endothelial function and a significant increase in the luminal diameter of the scaffold segment in response to vasoactive agents. ${ }^{(7)}$ The vessel recovers the ability to respond to physiological stimuli, which may translate into reduced anginal episodes and a better functional capacity than when the metallic DES is used. (b) In contrast to the metallic DES, the BRS has the potential for late lumen enlargement, starting at the resorption phase. Multimodality imaging has documented late lumen enlargement among patients in the ABSORB Cohort A and Cohort B trials. ${ }^{(7-9)}$ (c) Following the resorption phase, BRS struts are replaced by neointima, which resembles the thick fibrous cap of a de novo atherosclerotic lesion. ${ }^{(10,11)}$ The BRS may offer security in terms of stabilisation of a vulnerable plaque and possibly also prevent acute coronary syndrome, although further studies are necessary to determine whether this potential effect can be achieved. (d) After complete resorption, no foreign body is left in the vessel. Hence, the risks of very late stent thrombosis are potentially eliminated. (e) The BRS is relatively more transparent than the metallic DES and facilitates serial noninvasive imaging (coronary computed tomography and magnetic resonance imaging). (f) In patients needing repeat revascularisation, the BRS may permit surgeons to carry out an anastomosis of bypass grafts at distal segments.

\section{USE IN CLINICAL PRACTICE}

The first BRS used in humans was the Igaki-Tamai stent (Kyoto Medical Planning Co Ltd, Kyoto, Japan). ${ }^{(12)}$ Made from poly-Llactide monofilament, the Igaki-Tamai stent is a coil stent that has a zigzag helical design and is self-expandable when heated. The stent struts disappear within three years. Immediate and six-month results suggested the safety and efficacy of the novel Igaki-Tamai stent. ${ }^{(12)}$ Its main drawbacks are the need for an 8-French guiding catheter for stent delivery, the absence of antiproliferative drug elution, and the use of a heated contrast dye that may result in vessel wall injury. Further research and development of this stent was interrupted by the evolution of the DES. However, the longterm clinical outcomes of the Igaki-Tamai stent are reassuring ${ }^{(13)}$ and lay the foundation for studies on various BRSs.

The most extensively studied BRS to date is the BVS. It is composed of a balloon-expandable poly-L-lactide scaffold (150- $\mu \mathrm{m}$ thick), which degrades completely in 2-3 years, and a thin, bioabsorbable poly-D, L-lactide coating for controlled release of everolimus. Radiopaque platinum markers at each end of the scaffold enable clear visualisation on imaging. The BVS was first evaluated in the ABSORB clinical trials (Cohorts

${ }^{1}$ Department of Cardiology, National University Heart Centre, Singapore

Correspondence: Dr Huay Cheem Tan, Director and Senior Consultant, Department of Cardiology, National University Heart Centre, 1E Kent Ridge Road, NUHS Tower Block, Level 9, Singapore 119228. huay_cheem_tan@nuhs.edu.sg 
Table I. Randomised trials of the Absorb Bioresorbable Vascular Scaffold (BVS).

\begin{tabular}{|c|c|c|}
\hline Study & Aim & Primary endpoint \\
\hline ABSORB II(21) & Compare BVS vs. CoCr-EES & $\begin{array}{l}\text { Angiographic vasomotion at } 3 \mathrm{yr} \text {, and difference } \\
\text { in minimum lumen diameter after the index } \\
\text { procedure and at } 3 \mathrm{yr}\end{array}$ \\
\hline ABSORB III(22) & Compare the safety and efficacy of BVS vs. CoCr-EES & Target lesion failure at $1 \mathrm{yr}$ \\
\hline ABSORB Japan ${ }^{(23)}$ & $\begin{array}{l}\text { Compare the safety and efficacy of BVS vs. CoCr-EES prior to } \\
\text { complete bioresorption }\end{array}$ & Target lesion failure at $1 \mathrm{yr}$ \\
\hline ABSORB China(24) & Assess the clinical and angiographic efficacy of BVS vs. CoCr-EES & Angiographic in-segment late loss at $1 \mathrm{yr}$ \\
\hline EVERBIO II (25) & $\begin{array}{l}\text { Compare the performance of BVS vs. CoCr-EES and } \\
\text { biolimus-eluting stents in all-comer patients }\end{array}$ & Angiographic late lumen loss at $9 \mathrm{mth}$ \\
\hline TROFI II(26) & $\begin{array}{l}\text { Compare the arterial healing response at } 6 \mathrm{mth} \text { following the use } \\
\text { of BVS vs. CoCr-EES in patients with STEMI }\end{array}$ & $\begin{array}{l}\text { Optical frequency domain imaging-derived } \\
\text { healing score assessed at } 6 \mathrm{mth}\end{array}$ \\
\hline
\end{tabular}

CoCr-EES: cobalt-chromium everolimus-eluting stent; STEMI: ST-segment elevation myocardial infarction

$\mathrm{A}$ and $\mathrm{B})$ and showed encouraging results. ${ }^{(14,15)}$ Subsequently, a number of single-arm studies and a few randomised controlled studies were published.

The other BRS that has been evaluated in clinical studies is the DESolve ${ }^{\circledR}$ Scaffold (Elixir Medical Corporation, Sunnyvale, CA, USA). ${ }^{(16)}$ Similar to the BVS, it is composed of a poly-Llactide scaffold and elutes either antiproliferative myolimus (firstgeneration) or novolimus (second-generation). In comparison to other BRSs, the DESolve Scaffold is believed to have a wider range of expansion, with reduced risk of strut fracture and selfcorrection of minor malapposition.

\section{CURRENT SUPPORTIVE EVIDENCE}

The vast majority of data that supports the use of the BRS in humans comes from studies using the BVS. The first-generation BVS (BVS 1.0) was tested in a series of 30 patients from the ABSORB Cohort A study. ${ }^{(14)}$ Although the cohort demonstrated encouraging long-term outcomes, ${ }^{(7,17)}$ the first-generation BVS demonstrated a slightly higher rate of acute and late recoil. ${ }^{(18,19)}$ To overcome this limitation, the strut design and the polymer's manufacturing process was modified in the revised version (BVS 1.1). This was tested in 101 patients from the ABSORB Cohort B study. Alteration of the scaffold design led to a significant improvement in the immediate and medium-term outcomes of this novel second-generation BVS. ${ }^{(15)}$ This paved the way for the conduct of a randomised controlled trial comparing the BVS with the metallic DES. A five-year follow-up study on the same cohort of patients (i.e. Cohort B) yielded low rates of restenosis and major adverse cardiac events. ${ }^{(20)}$ To date, there have been six randomised trials that compared the BVS with the DES. The various studies are illustrated in Table I.

ABSORB II was the first randomised controlled trial comparing the Absorb BVS with the XIENCE V cobalt-chromium everolimuseluting stent (CoCr-EES; Boston Scientific, Marlborough, MA, USA). The co-primary endpoints of this study were the assessment of vasomotion at three years and the difference between the minimum lumen diameter after the index procedure and at three years. In the interim one-year analysis, the Absorb BVS showed a similar clinical outcome as the CoCr-EES. ${ }^{(21)}$ However, the study was not adequately powered for clinical endpoints. The two-year follow-up data from this trial was reported at the Transcatheter Cardiovascular Therapeutics 2015 conference. Although the patient-oriented composite endpoint did not differ between the two groups, target lesion failure (a composite of cardiac death, target-vessel myocardial infarction and clinically indicated targetlesion revascularisation) was significantly higher in the BVS group (BVS 7.0\% vs. CoCr-EES 3.0\%; p = 0.07).

ABSORB III ${ }^{(22)}$ evaluated the relative safety and efficacy of the Absorb BVS versus the CoCr-EES in patients with coronary artery disease. The primary endpoint was target lesion failure (a composite of cardiac death, target-vessel myocardial infarction or ischaemia-driven target-lesion revascularisation) at one year. Target lesion failure occurred in $7.8 \%$ of patients in the Absorb group and $6.1 \%$ of patients in the CoCr-EES group $(p=0.007$ for non-inferiority; $p=0.16$ for superiority). ${ }^{(22)}$ Despite the performance of the Absorb BVS being comparable to that of the $\mathrm{CoCr}$-EES, there were some concerns. The overall device thrombosis rate was reported to be higher in the Absorb group than in the CoCr-EES group $(1.5 \%$ vs. $0.7 \%)$, although the difference was not significant. In comparison to the CoCr-EES group, the rate of subacute device thrombosis was significantly greater in the Absorb group. ${ }^{(22)}$ One of the important limitations of the ABSORB III study was its inability to examine low-frequency events such as cardiac death and device thrombosis. Clinical follow-up in this trial will be performed for five years and the results are awaited.

An overview of all trials on BVS showed no significant difference in one-year outcomes between the BVS and CoCr-EES for most endpoints. A pooled meta-analysis of four randomised trials showed similar results for both the BVS and CoCr-EES in patient- and device-oriented composite endpoints at one year. ${ }^{(27)}$ The BVS was developed to circumvent the limitations of the metallic DES, which are evident after one year of implantation. Imaging evidence supports the novel attributes of the BVS, ${ }^{(7,8)}$ but improved late clinical outcomes are required to definitively show the superior benefit of the BVS, as compared to the metallic DES. Hence, the results are not expected to become obvious until 3-5 years after implantation, and there is a need to wait for the clinical outcomes of ongoing large-scale randomised trials (e.g. ABSORB IV). 
Data from multiple single-arm trials have provided reassurance of the safety and efficacy of the BVS. Interim analysis of the ABSORB EXTEND study revealed low rates of major adverse cardiac events and scaffold thrombosis at one year. ${ }^{(28)}$ Although the majority of studies on the BVS have been on stable patients and simple lesions, with better understanding of the BVS and improved operator expertise, it is now being used in complex lesion subsets. There is data on the application of the BVS in acute coronary syndrome, ${ }^{(21,26,28,29)}$ bifurcation lesions, ${ }^{(30,31)}$ left main disease, ${ }^{(32,33)}$ chronic total occlusion, ${ }^{(34)}$ calcific lesions, ${ }^{(35)}$ in-stent restenosis ${ }^{(36)}$ and multi-vessel disease. ${ }^{(37)}$

\section{IMPLANTATION TECHNIQUE}

The design and properties of the BVS are different from that of the metallic DES. Hence, appropriate technique for BVS implantation is vital for procedural success and clinical outcomes. A consensus has been reached on the optimal implantation procedure, and the key points are listed as follows. ${ }^{(38,39)}$

\section{Preparation of lesion}

Predilatation of the lesion should be accomplished with a suitably sized balloon that matches the reference vessel diameter (sized 1:1). The BVS should not be implanted into lesions that have suboptimal results after predilatation (i.e. residual stenosis $>40 \%$ ). If the predilatation results are unsatisfactory, BVS deployment will result in underexpansion and a predisposition to scaffold thrombosis and restenosis.

\section{Proper sizing of vessel}

Accurate vessel sizing before scaffold deployment is crucial for a favourable procedural outcome. Imaging with intravascular ultrasonography or optical coherence tomography is ideal for analysis of the vessel and selection of the scaffold size. It may not be practical to perform intravascular imaging in all cases; an assessment of the angiogram comparing the vessel lumen with the dimensions of the guiding catheter is reasonable. In addition, the balloon that is used for predilatation (sized 1:1) can be useful for scaffold sizing. The scaffold should cover at least $2 \mathrm{~mm}$ of the healthy vessel at either edge of the lesion.

\section{Consideration of expansion limit}

The BVS expansion limit is $0.5 \mathrm{~mm}$ above the nominal size. A 3.0-mm BVS should not be dilated beyond $3.5 \mathrm{~mm}$, above which the struts are likely to fracture.

\section{Post-dilatation with noncompliant balloon}

Routine post-dilatation with a noncompliant balloon at high pressure is recommended for optimal outcome.

\section{Prescription of dual antiplatelet therapy}

Dual antiplatelet therapy should be prescribed as per the guidelines.

In contrast to metal stents, the deployment of the BVS must occur gradually (balloon inflation of $2 \mathrm{~atm}$ at every fifth second) until complete expansion. The deployed pressure should be maintained for at least 30 seconds. A successful procedure should result in no significant residual stenosis $(<10 \%)$, total scaffold expansion and optimal strut apposition without complications. Many interventional cardiologists are still not familiar with the appropriate techniques of BVS implantation. The procedure is not straightforward and requires a learning period for operators to be familiar with the technique. Ideally, new users of the BVS should gradually build up their expertise, starting with stable patients and simple lesions, and as experience is gained, they may attempt the procedure on more complex lesions.

\section{DRAWBACKS AND CONCERNS}

The drawbacks of the BRS are related to the mechanical properties of the scaffold structure and the technique of stent implantation. The higher strut thickness limits deliverability and increases nonlaminar flow, and the higher crossing profile restricts its use in difficult anatomical settings. The strut thickness of the BRS may result in more frequent side-branch occlusions and contribute to periprocedural myocardial infarction. ${ }^{(40)}$ Early causes of BRS failure include scaffold dislodgement, acute recoil and scaffold thrombosis. Scaffold dislodgement has principally been reported in lesions that are not adequately predilated and on the second insertion of the same scaffold. ${ }^{(41)}$ Early scaffold thrombosis reported in the GHOST-EU registry ${ }^{(37)}$ suggests that there is scope for improvement in terms of lesion selection and optimisation of BRS implantation. Acute recoil of the BRS is another important drawback related to improper stent implantation technique. ${ }^{(42)}$

Very late stent thrombosis events are not expected in view of complete resorption of the BRS. However, such events have been documented in the literature and may indicate delayed healing, with the need to continue dual antiplatelet therapy beyond the first year. ${ }^{(43)}$ There is no convincing data or evidence in favour of shortening the duration of dual antiplatelet therapy in BRSimplanted individuals. Neoatherosclerosis, scaffold restenosis and acquired coronary aneurysm are the other late causes of BRS failure. ${ }^{(44,45)}$

\section{CONCLUSION}

The concept of the BRS is logical and attractive. The short- and medium-term results are encouraging, but its long-term safety remains unknown. Therefore, more randomised long-term clinical data will be required to determine whether the theoretical advantage of the BRS can translate into routine practice. The superiority of the BRS over the second-generation DES has not been proven. Use of the BRS can be considered in a carefully selected group of individuals (e.g. young patients, lesions without significant calcification and tortuosity, long lesions, multi-vessel disease and lesions with spontaneous coronary artery dissection), with strict adherence to an optimal implantation technique.

\section{REFERENCES}

1. Bourantas $C V$, Zhang $Y$, Farooq V, et al. Bioresorbable scaffolds: current evidence and ongoing clinical trials. Curr Cardiol Rep 2012; 14:626-34.

2. Finn AV, Nakazawa G, Joner $M$, et al. Vascular responses to drug eluting stents: importance of delayed healing. Arterioscler Thromb Vasc Biol 2007; 27:1500-10. 
3. Nakazawa G, Ladich E, Finn AV, Virmani R. Pathophysiology of vascular healing and stent mediated arterial injury. Eurolntervention 2008; 4 Suppl C: C7-10.

4. Nakazawa G, Otsuka F, Nakano M, et al. The pathology of neoatherosclerosis in human coronary implants bare-metal and drug-eluting stents. J Am Coll Cardiol 2011; 57:1314-22.

5. Joner M, Finn AV, Farb A, et al. Pathology of drug-eluting stents in humans: delayed healing and late thrombotic risk. J Am Coll Cardiol 2006; 48:193-202.

6. Oberhauser JP, Hossainy S, Rapoza RJ. Design principles and performance of bioresorbable polymeric vascular scaffolds. Eurolntervention 2009; 5 Suppl F: F15-22.

7. Serruys PW, Ormiston JA, Onuma Y, et al. A bioabsorbable everolimus-eluting coronary stent system (ABSORB): 2-year outcomes and results from multiple imaging methods. Lancet 2009; 373:897-910.

8. Onuma Y, Dudek D, Thuesen L, et al. Five-year clinical and functional multislice computed tomography angiographic results after coronary implantation of the fully resorbable polymeric everolimus-eluting scaffold in patients with de novo coronary artery disease: the ABSORB cohort A trial. JACC Cardiovasc Interv 2013; 6:999-1009.

9. Serruys PW, Onuma Y, Dudek D, et al. Evaluation of the second generation of a bioresorbable everolimus-eluting vascular scaffold for the treatment of de novo coronary artery stenosis: 12-month clinical and imaging outcomes. J Am Coll Cardiol 2011; 58:1578-88

10. Bourantas CV, Serruys PW, Nakatani S, et al. Bioresorbable vascular scaffold treatment induces the formation of neointimal cap that seals the underlying plaque without compromising the luminal dimensions: a concept based on serial optical coherence tomography data. Eurolntervention 2015; 11:746-56.

11. Brugaletta S, Radu MD, Garcia-Garcia HM, et al. Circumferential evaluation of the neointima by optical coherence tomography after ABSORB bioresorbable vascular scaffold implantation: can the scaffold cap the plaque? Atherosclerosis 2012; 221:106-12.

12. Tamai $\mathrm{H}$, Igaki $\mathrm{K}$, $\mathrm{Kyo} \mathrm{E}$, et al. Initial and 6-month results of biodegradable poly-l-lactic acid coronary stents in humans. Circulation 2000; 102:399-404.

13. Nishio S, Kosuga K, Igaki K, et al. Long Term (>10 Years) clinical outcomes of first-in-human biodegradable poly-I-lactic acid coronary stents: IgakiTamai stents. Circulation 2012; 125:2343-53.

14. Ormiston JA, Serruys PW, Regar E, et al. A bioabsorbable everolimus-eluting coronary stent system for patients with single de-novo coronary artery lesions (ABSORB): a prospective open-label trial. Lancet 2008; 371:899-907.

15. Serruys PW, Onuma Y, Ormiston JA, et al. Evaluation of the second generation of a bioresorbable everolimus drug-eluting vascular scaffold for treatment of de novo coronary artery stenosis: six-month clinical and imaging outcomes. Circulation 2010; 122:2301-12.

16. Abizaid A, Costa RA, Schofer J, et al. Serial multimodality imaging and 2-year clinical outcomes of the novel DESolve novolimus-eluting bioresorbable coronary scaffold system for the treatment of single de novo coronary lesions. JACC Cardiovasc Interv 2016; 9:565-74.

17. Onuma Y, Serruys PW, Ormiston JA, et al. Three-year results of clinical follow-up after a bioresorbable everolimus-eluting scaffold in patients with de novo coronary artery disease: the ABSORB trial. Eurolntervention 2010; 6:447-53.

18. Tanimoto S, Serruys PW, Thuesen L, et al. Comparison of in vivo acute stent recoil between the bioabsorbable everolimus-eluting coronary stent and the everolimus-eluting cobalt chromium coronary stent: insights from the ABSORB and SPIRIT trials. Catheter Cardiovasc Interv 2007; 70:515-23.

19. Tanimoto S, Bruining N, van Domburg RT, et al. Late stent recoil of the bioabsorbable everolimus-eluting coronary stent and its relationship with plaque morphology. J Am Coll Cardiol 2008; 52:1616-20.

20. Serruys PW, Ormiston J, van Geuns RJ, et al. A polylactide bioresorbable scaffold eluting everolimus for treatment of coronary stenosis: 5-year follow-up. J Am Coll Cardiol 2016; 67:766-76.

21. Serruys PW, Chevalier B, Dudek D, et al. A bioresorbable everolimus-eluting scaffold versus a metallic everolimus-eluting stent for ischaemic heart disease caused by de-novo native coronary artery lesions (ABSORB II): an interim 1-year analysis of clinical and procedural secondary outcomes from a randomised controlled trial. Lancet 2015; 385:43-54.

22. Ellis SG, Kereiakes DJ, Metzger DC, et al; ABSORB III Investigators. Everolimuseluting bioresorbable scaffolds for coronary artery disease. N Engl J Med 2015; 373:1905-15.

23. Kimura T, Kozuma K, Tanabe $\mathrm{K}$, et al; ABSORB Japan Investigators A randomized trial evaluating everolimus-eluting Absorb bioresorbable scaffolds vs. everolimus-eluting metallic stents in patients with coronary artery disease: ABSORB Japan. Eur Heart J 2015; 36:3332-42.

24. Gao R, Yang Y, Han Y, et al; ABSORB China Investigators. Bioresorbable vascular scaffolds versus metallic stents in patients with coronary artery disease: ABSORB China trial. J Am Coll Cardiol 2015; 66:2298-309.

25. Puricel S, Arroyo D, Corpataux N, et al. Comparison of everolimus- and biolimuseluting coronary stents with everolimus-eluting bioresorbable vascular scaffolds. J Am Coll Cardiol 2015; 65:791-801.

26. Sabaté $M$, Windecker $S$, Iñiguez $A$, et al. Everolimus-eluting bioresorbable stent vs. durable polymer everolimus-eluting metallic stent in patients with ST-segment elevation myocardial infarction: results of the randomized ABSORB ST-segment elevation myocardial infarction-TROFI II trial. Eur Heart J 2016; 37:229-40.

27. Stone GW, Gao R, Kimura T, et al. 1-year outcomes with the Absorb bioresorbable scaffold in patients with coronary artery disease: a patient-level, pooled metaanalysis. Lancet 2016; 387:1277-89.

28. Abizaid A, Ribamar Costa J Jr, Bartorelli AL, et al; ABSORB EXTEND investigators. The ABSORB EXTEND study: preliminary report of the twelvemonth clinical outcomes in the first 512 patients enrolled. Eurolntervention 2015; 10:1396-401.

29. Kajiya T, Liang M, Sharma RK, et al. Everolimus-eluting bioresorbable vascular scaffold (BVS) implantation in patients with ST-segment elevation myocardial infarction (STEMI). Eurolntervention 2013; 9:501-4.

30. Shah A, Chan W, Overgaard C, Ing D, Dzavik V. Safety and feasibility of everolimus-eluting bioresorbable vascular scaffold in the treatment of coronary bifurcation lesions. JACC Cardiovasc Interv 2015; 8(Suppl 2):S18.

31. Seth A, Sengottuvelu G, Ravisekar V. Salvage of side branch by provisional "TAP technique" using ABSORB $^{\text {TM }}$ bioresorbable vascular scaffolds for bifurcation lesions: first case reports with technical considerations. Catheter Cardiovasc Interv 2014; 84:55-61.

32. Cortese B, Orrego PS, Sebik R, et al; RAI registry investigators. Biovascular scaffolding of distal left main trunk: experience and follow up from the multicenter prospective RAI registry (Registro Italiano Absorb). Int J Cardiol 2014; 177:497-9.

33. Sato K, Latib A, Panoulas VF, et al. A case of true left main bifurcation treated with bioresorbable everolimus-eluting stent v-stenting. JACC Cardiovasc Interv 2014; 7:e103-4.

34. Ojeda S, Pan M, Romero M, et al. Outcomes and computed tomography scan follow-up of bioresorbable vascular scaffold for the percutaneous treatment of chronic total coronary artery occlusion. Am J Cardiol 2015; 115:1487-93.

35. Basavarajaiah S, Naganuma T, Latib A, Colombo A. Can bioabsorbable scaffolds be used in calcified lesions? Catheter Cardiovasc Interv 2014; 84:48-52.

36. Alfonso F, Nuccio J, Cuevas C, et al. Treatment of coronary in-stent restenosis with bioabsorbable vascular scaffolds. J Am Coll Cardiol 2014; 63(25 Pt A):2875.

37. Capodanno D, Gori $\mathrm{T}$, Nef $\mathrm{H}$, et al. Percutaneous coronary intervention with everolimus-eluting bioresorbable vascular scaffolds in routine clinical practice: early and midterm outcomes from the European multicentre GHOSTEU registry. Eurolntervention 2015; 10:1144-53.

38. Tamburino C, Latib A, van Geuns RJ, et al. Contemporary practice and technical aspects in coronary intervention with bioresorbable scaffolds: a European perspective. Eurolntervention 2015; 11:45-52.

39. Rizik DG, Hermiller JB, Kereiakes DJ. The ABSORB bioresorbable vascular scaffold: A novel, fully resorbable drug-eluting stent: Current concepts and overview of clinical evidence. Catheter Cardiovasc Interv 2015; 86:664-77.

40. Muramatsu T, Onuma Y, García-García HM, et al; ABSORB-EXTEND Investigators. Incidence and short-term clinical outcomes of small side branch occlusion after implantation of an everolimus-eluting bioresorbable vascular scaffold: an interim report of 435 patients in the ABSORB-EXTEND single-arm trial in comparison with an everolimus-eluting metallic stent in the SPIRIT first and II trials. JACC Cardiovasc Interv 2013; 6:247-57.

41. Ishibashi $Y$, Onuma $Y$, Muramatsu $T$, et al; ABSORB EXTEND Investigators. Lessons learned from acute and late scaffold failures in the ABSORB EXTEND trial. Eurolntervention 2014; 10:449-57.

42. Danzi GB, Sesana M, Arieti M, et al. Does optimal lesion preparation reduce the amount of acute recoil of the Absorb BVS? Insights from a real-world population. Catheter Cardiovasc Interv 2015; 86:984-91.

43. Timmers L, Stella PR, Agostoni P. Very late bioresorbable vascular scaffold thrombosis following discontinuation of antiplatelet therapy. Eur Heart J 2015; 36:393.

44. Mangiameli A, Ohno Y, Attizzani GF, Capodanno D, Tamburino C. Neoatherosclerosis as the cause of late failure of a bioresorbable vascular scaffold. JACC Cardiovasc Interv 2015; 8:633-4.

45. La Manna A, Mangiameli A, Capodanno D, et al. Managing bioabsorbable vascular scaffold failure: combined scaffold restenosis and late-acquired coronary aneurysm treated with self-expandable stent. Can J Cardiol 2015; 31:691.e1-3. 